\title{
DOSSIER
}

Configuraciones militantes contemporáneas.

Una propuesta metodológica para pensar el compromiso político*

Contemporary militant configurations.

A methodological proposal to think about political commitment

Fernando Aiziczon ${ }^{1}$

RESUMEN En este artículo proponemos

una manera posible de pensar la militancia

política en su vínculo con el problema del

compromiso político y la acción. Luego de

presentar estas relaciones, problematizamos la

idea de configuraciones militantes, sugiriendo

parámetros de referencia aplicables al caso de

la militancia de izquierdas en la Argentina con-

temporánea e interrogando sobre los quiebres

y continuidades que habilitan el despliegue de

formas de militancia en determinados contex-

tos históricos. Trabajamos sobre la hipótesis

de que el debate reciente sobre la violencia

revolucionaria en las organizaciones político-

militares de los años sesenta-setenta, super-

puesto con las discusiones emergentes tras la

crisis sociopolítica de 2001, señalarian las con-

diciones de posibilidad para la emergencia de

una nueva configuración militante de carácter

transicional en la época actual.

Palabras clave: Configuraciones militantes-

compromiso político-acción-historia argenti-

na contemporánea-violencia revolucionaria-

crisis sociopolitica de 2001

D01: http://dx.doi.org/10.30972/dpd.792805

\section{COMPROMISO Y ACCIÓN}

Creo que vivir quiere decir tomar partido. Quien verdaderamente vive, no puede dejar de ser ciudadano y partisano (...) Lo que sucede, el mal que se abate sobre todos, acontece porque la masa de los hombres abdica de su voluntad (...) nadie o muy pocos se preguntan: ¿si hubiera tratado de hacer valer mi voluntad, habría pasado lo que ha pasado?

Antonio Gramsci, Odio a los indiferentes, 1917.

La reflexión no puede detener el impulso de nuestra espontaneidad. El hombre planta, lucha, conquista, desea, ama, pero siempre hay un ¿“y después?” (...) ¿Cuál es pues la medida de un hombre?, ¿Qué fines puede proponerse y qué esperanzas le están permitidas?

Simone De Beauvoir, ¿Para qué la acción?, 1944.

Entre 1850 y 1920 se pasa del progresismo histórico al heroísmo político histórico, porque se pasa de la confianza a la desconfianza. El proyecto del hombre nuevo impone la idea de que vamos a obligar a la historia, a forzarla. El siglo XX es un siglo voluntarista. Digamos que es el siglo paradójico de un historicismo voluntarista.

Alain Badiou, El siglo, 2005.

Entre el "tomar partido" al modo imperativo de Gramsci, donde vivir es posicionarse políticamente y por lo tanto ejercer la voluntad propia, y la cuestión de orden existencial planteada por De Beauvoir, donde la acción es subsidiaria de la pregunta por el después, es posible trazar un horizonte reflexivo sobre el modo en que el compromiso político y la acción -individual, colectiva- ha sido delineada en las sociedades modernas occidentales, más específicamente a cómo se la presentó al interior de la cultura política de las izquierdas en sentido amplio, toda vez que se entienda al pensamiento y acción de izquierdas como crítico e impugnador del orden social dominante (vg. capitalista)
* Este trabajo fue recibido el 22 de septiembre de 2017 y aceptado para su publicación el 29 de diciembre de 2017.

${ }^{1}$ Dr. en Historia, investigador en el IDH-Conicet, Universidad Nacional de Córdoba. Correo electrónico: feraizic@gmail.com 
De Prácticas y discursos

Universidad Nacional del Nordeste

Centro de Estudios Sociales

Año 7, Número 9, 2018, Marzo

ISSN 2250-6942

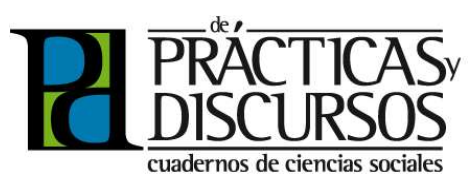

en primer término, y como generador de formas de acción que comprometan a los sujetos para alcanzar el objetivo de una sociedad alternativa ${ }^{2}$. Prescindiendo a efectos pedagógicos de los contextos en los cuales fueron enunciadas -y de la crítica interna que el pensamiento de izquierdas ha elaborado alrededor de su propia experiencia histórica-, entre la apelación gramsciana a los que dudan -y por lo tanto ejercen el descompromiso político- y aquellos que se preguntan por el sentido último de la acción -pregunta donde resulta inadecuado pensar si se toma o no partido, sino simplemente por qué se decide realizar una acción- existe una zona gris señalada por Badiou donde la salida transitoria al dilema del por qué involucrarse implica forzar o intervenir a pesar de ello, es decir, obrando a voluntad para conjurar la desconfianza que la Historia sembraba de modo implacable a través del siglo XX. La desconfianza, no está demás aclararlo, refiere a que sin el concurso de la voluntad militante -y más luego, a pesar de ella- la Historia por sí sola no traería el mejor de los mundos posibles, o siquiera un mundo algo más justo (Traverso, 2017).

\section{CONFIGURACIONES MILITANTES COMO MÉTODO PARA APRENDER LAS FORMAS DE COMPROMISO Y ACCIÓN}

No obstante ello, el problema del compromiso político y la acción es abordable si se cambia la posición de análisis hacia la aprehensión de los modos en que efectivamente se practica el compromiso a través de la práctica de la militancia política, incorporando también la forma específica que adquiere ese llamado a la acción o esa apelación a la voluntad del sujeto, esto es, prestar atención a las dimensiones que confluyen en la construcción de ese tipo particular de acción llevada a cabo por lo que denominamos militantes, y en el mismo movimiento, reconstruir cierta configuración o perfiles militantes históricos sobre los cuales resulta posible cruzar, de modo tentativo, las siguientes variables: 1) El sujeto militante que encarna o simboliza la acción; 2) la forma organizativa hegemónica para organizar, incentivar y sostener el compromiso y la acción; 3) el modo de estudio de esa militancia relacionado con el tipo de fuente de análisis disponible, en otras palabras, la reflexividad sobre cómo conocemos la militancia. Esta última variable adquiere un plus de sentido si se considera que el estudio de la militancia de izquierdas en particular ha implicado 
De Prácticas y discursos

Universidad Nacional del Nordeste

Centro de Estudios Sociales

Año 7, Número 9, 2018, Marzo

ISSN 2250-6942
Configuraciones militantes contemporáneas.

Una propuesta metodológica para pensar el compromiso político

Contemporary militant configurations. A methodological proposal to think about political commitment
${ }^{3}$ Quizás, el caso más paradigmático sea el de la proletarización voluntaria de Simone Weil (2010) en las fábricas Alsthom y Renault durante 1934 y 1935, narrado en su libro La condición obrera. Sobre la empatía entre investigadores dentro del campo historiográfico, puede consultarse Pozzi (2013) y Hobsbawm (1978). no pocas veces en una adhesión a la causa más o menos explícita de parte de los estudiosos del tema; esto es, los que han estudiado la acción de los militantes en general lo hicieron también como una forma de compromiso explícita con su objeto y la causa que decía representar, generando aquello que los antropólogos denominan "alteridad mínima" (Peirano, 1995).

Va de suyo que una variable histórica que dé cuenta de por qué existe una determinada configuración militante para una determinada estructura social (obrero, campesino, mujer, "ciudadano global", etc.) resulta ineludible al momento de explicar estas tres variables propuestas, en especial al interior del campo de la izquierda, muy afecta a cuestiones como la caracterización histórica, el sujeto hegemónico, la estrategia, etc. Lo que proponemos entonces es una problematización que caracterice perfiles militantes y formas de compromiso político históricamente situados. A estos perfiles proponemos analizarlos, siguiendo a Pudal (2011), bajo la idea de configuraciones militantes, es decir, prácticas, valores, ideologías que constituyen un modo histórico especifico de practicar la militancia, como asi también la forma en que determinadas corrientes teóricas las estudian o dan cuenta de ellas, porque se considera que además forman parte de la construcción de una configuración militante determinada. La noción de configuraciones militantes permite establecer perfiles históricos determinados sobre la base de un análisis que cruza variables tales como las ya mencionadas de sujeto, tipo de organizaciones sobre las que se despliega una militancia, contexto político donde se desarrolla, los paradigmas analíticos mediante los cuales se estudia el fenómeno de la militancia, ya sea desde las ciencias sociales o desde el propio campo militante, entre otras variables posibles.

Por su parte, los modos de compromiso político expresan también estructuras de sentimientos epocales (Williams, 1980) relacionadas con otras tantas maneras de concebir la organización politica; de alli que algunos investigadores intenten formular perfiles militantes cronológicamente ubicables a modo de "configuraciones" que se diferencian unas de otras.

\section{TIPOS HISTÓRICOS DE CONFIGURACIONES MILITANTES}

Según Pudal, quien traza un esquema para la historia francesa interesante de pensar en nuestras latitudes, podriamos hablar 
De Prácticas y discursos

Universidad Nacional del Nordeste

Centro de Estudios Sociales

Año 7, Número 9, 2018, Marzo

ISSN 2250-6942

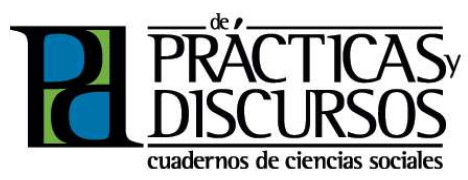

\begin{abstract}
${ }^{4}$ En particular, el $\mathrm{PCl}$ ha sido ejemplar en la producción de autobiografías críticas, entre muchos destacamos a Rossanda (2008), Magri (2011), y en el caso del PC argentino, a Gilbert (2009), Nadra (2013), y dentro del trotskismo, a Almeyra (2013), Pereyra (2014), entre otros. Un trabajo clásico sobre generaciones militantes que lucharon por los derechos civiles en EEUU es el de McAdam, Freedom Summer, publicado a mediados de los sesenta.
\end{abstract}

de una configuración de tipo "heroica" para el período 19451975, simbolizada en la figura del activista obrero, militante del partido comunista francés (PCF) y generalmente narrado bajo la impronta de biografias y autobiografías que describen un sujeto altruista que entrega su vida a la acción en pos de un cambio social revolucionario. Una segunda configuración se ubica entre 1975-1990 y es denominada como el período del militante "retribuido", esto es, si la anterior configuración mostraba el valor de la voluntad "desinteresada" del militante, ahora estamos frente a un desencanto con esa operación de idealización. ¿Por qué?, el acontecimiento histórico que provoca una fuerte transformación del tipo militante anterior y una revisión del modo de abordaje de la militancia en general es el cimbronazo político posterior al Mayo del 68: evento bisagra en la historia política francesa -y mundial- que marca el inicio de una larga crisis del movimiento huelguístico y que impacta en la legitimidad del PCF -que sufre desafiliaciones masivas- y colateralmente afecta al alcance del marxismo como llave teórica para explicar la acción política en las izquierdas. La "clase", el "Partido", el "sujeto obrero", el "sindicato", reciben duras críticas: su centralidad es cuestionada y reemplazada por nuevas organizaciones, quedando aquellas lentamente relegadas a formas "clásicas" de concebir el compromiso político, a pesar de que su legitimidad y funcionalidad reaparezcan persistentemente hasta la actualidad. De todos modos, desde entonces deben competir con otras instancias tales como los emergentes "nuevos movimientos sociales". Lo central en términos de configuraciones militantes es que aquel militante heroico ya no será concebido de ese modo: ahora el sujeto militante es alguien motivado por intereses o "incitaciones selectivas" (Olson, 1966), pues se trata de un militante "retribuido" de diversos modos que refuerzan su elección, elección que es puesta bajo un signo de interrogación respecto de lo que está en juego en la "entrega" militante. Así, la biografía militante de tono edificante da paso a la autobiografía crítica, mientras que en el campo académico emergen trabajos sobre la base de encuestas que intentan establecer variables y atributos explicativos del compromiso político ${ }^{4}$.

De resultas de estas modificaciones, una tercera configuración irrumpe en torno a los años noventa caracterizada por la aparición de "nuevos militantes", o si se prefiere, la figura del militante "distanciado" que nutre organizaciones ambientalistas, 
De Prácticas y discursos

Universidad Nacional del Nordeste

Centro de Estudios Sociales

Año 7, Número 9, 2018, Marzo

ISSN 2250-6942
Configuraciones militantes contemporáneas.

Una propuesta metodológica para pensar el compromiso político

Contemporary militant configurations. A methodological proposal to think about political commitment

altermundistas, autonomistas, de género, etc.; su contexto son las huelgas francesas de 1995 en donde predomina un tipo de compromiso que es estudiado bajo novedosas perspectivas que se suman a los aportes fundamentales de Pierre Bourdieu (2001) sobre la crítica a la delegación y el fetichismo de la política. Pero, además, una nueva generación de investigadores anglosajones y norteamericanos son contemporáneos a estos y otros procesos inmediatamente previos, tales como la caída de los regímenes comunistas en los paises del este europeo. Tilly (2008) y su teoría del proceso político, Goffman (2006) y su teoría del framing, o la perspectiva que estudia repertorios de movilización y estructuras de oportunidades políticas (Mc Adam, McCarthy, Zald, 1996; Tarrow, 1998), autores como Snow, James Scott, entre otros, se caracterizan por conformar redes de investigadores o editar revistas especializadas como la norteamericana Mobilization. Ya no hablamos tanto de biografías, sino de artículos académicos, tesis, informes de investigación, e incluso cierta autonomización de objetos de estudio como la "protesta social" o la movilización como fenómeno de estudio (Fillieule y Tartakowsky, 2015). Si bien aquí importan múltiples variables de análisis, se destacan los abordajes respecto del trabajo cognitivo de los militantes, el despliegue de sus "carreras" y trayectorias.

En este contexto es lógico suponer que lo que predomina es el desencanto con la figura del militante heroico, un desencanto muy a tono con cierto giro a la derecha en el campo intelectual francés pos caída del Muro de Berlín y que recibirá un nuevo impulso con el debate que abre la obra de Jacques Ion titulada La fin des militants (1997), quien luego de criticar al militante clásico, al que asocia con un modelo de compromiso totalitario, propone la idea del "militante distanciado", necesario relevo del anterior, y cuya tesis central postula la crisis del modelo militante tradicional que ahora se enfrenta a un contexto de acentuado individualismo (compromisos políticos menos intensos, negación a sacrificar la vida privada en pos de un ideal revolucionario), reforzado por una escasa voluntad de asociación, si bien muy relacionada con las particularidades del espacio público francés, pero que pueden revisarse en contextos diversos si se atiende a la emergencia de agrupaciones informales y descentralizadas que debilitan el impulso necesario para el despliegue de una sociabilidad militante clásica. Con sus críticas, de las que sobresale un desprecio hacia el modelo militante tradicional, el debate que 
De Prácticas y discursos

Universidad Nacional del Nordeste

Centro de Estudios Sociales

Año 7, Número 9, 2018, Marzo

ISSN 2250-6942

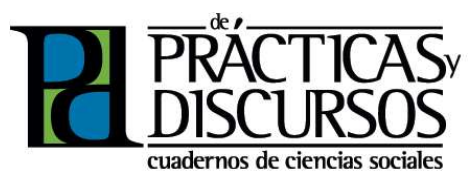

\begin{abstract}
${ }^{5}$ Descontando que el objetivo no está circunscripto al estudio de la militancia, pero sí responde a cierta inquietud en la cultura de izquierdas local, podríamos pensar en la aparición de revistas como Lucha Armada entre 2005-2014, en la emergencia de centros de documentación como el Cedinci (Centro de Documentación e Investigación de la Cultura de lzquierdas en la Argentina), el Cehti (Centro de Estudios Históricos de los Trabajadores y la lzquierda) o en la edición del Diccionario Biográfico de la lzquierda Argentina (Tarcus, 2007) basado en el modelo francés de diccionario biográfico del movimiento obrero editado por Jean Maitron.
\end{abstract}

aún produce la obra de lon contiene indicaciones relevantes tales como el rechazo a considerar al discurso de los agentes como la verdad de sus prácticas, y el cuestionamiento a cierta predisposición analítica que otorga a la biografía la condición explicativa primordial para dar cuenta del paso al compromiso político. Finalmente, en la actualidad estariamos frente a una cuarta configuración militante, transicional o en tono de interrogación, que se caracterizaría por la dificultad existente a la hora de definir un sujeto militante homogéneo al haberse ampliado considerablemente el campo de las militancias practicadas y estudiadas, aunque se mantiene a fines heurísticos la comparación entre la figura del clásico activista obrero con la del militante distanciado. Se trata de formas marcadas por periodos de interés-desinterés, mixturas de individualismo con destellos de disposiciones militantes renovadas, experiencias que combinan diversos modos de retribuciones con la búsqueda consciente de compromiso político, entre otros rasgos, y que exigen un estudio procesual de la militancia incorporando incluso otras militancias antes descuidadas, como la que practican los partidos de derecha, las organizaciones humanitarias, $\mathrm{ONG}$, entre otras. Veamos a continuación una propuesta tentativa para pensar el contexto argentino.

\section{CONFIGURACIONES MILITANTES EN LA IZOUIERDA ARGENTINA: UN ESOUEMA TENTATIVO}

El esquema histórico que presenta Pudal nos sirve para pensar e identificar posibles configuraciones militantes para el caso argentino, a sabiendas de que ninguna organización de la izquierda local alcanzó el grado de hegemonía ni de representatividad que sí tuvo el PC en Francia. En otro plano, tampoco es comparable la magnitud ni la trayectoria de los estudios sobre militancia, cuestión que en la Argentina recién comienza a transitarse, como veremos, de modo poco sistemático en las últimas décadas y bajo la marca especifica que le otorga el debate sobre la violencia revolucionaria en los sesenta-setenta ${ }^{5}$.

Distinguiremos configuraciones militantes sobre la base de tres variables: el sujeto militante (1), la organización en la que activa (2), y el modo en que se da cuenta de la existencia del compromiso político (3); esta última variable incluye tanto la producción escrita como los intentos de estudiarlas, que pueden provenir tanto del campo militante como del campo académico. La intersección en- 
De Prácticas y discursos

Universidad Nacional del Nordeste

Centro de Estudios Sociales

Año 7, Número 9, 2018, Marzo

ISSN 2250-6942
Configuraciones militantes contemporáneas.

Una propuesta metodológica para pensar el compromiso político

Contemporary militant configurations.

A methodological proposal to think about political commitment

\begin{abstract}
${ }^{6}$ En la historia argentina sobresale el intento crítico de José Aricó (1999), que cruza notablemente los problemas de la militancia política a través de las derivas del PCA, las dificultades de la teoría marxista en Latinoamérica y la reflexión del rol del intelectual en las democracias de transición, en especial tras su exilio en México.
\end{abstract}

${ }^{7}$ Un registro de biografía clásica puede encontrarse en el libro del militante comunista Luis Sommi (1946), titulada Neuquén, la vida de los presos políticos, o en Enrique Dickmann (1949), Recuerdos de un militante socialista. Cabría postular que en realidad este periodo que podríamos llamar "heroico" se extiende hacia atrás bajo la hegemonía política del anarquismo y luego del sindicalismo revolucionario en las primeras décadas del siglo XX (Oved, 1978; Suriano, 2002). tre sujeto, organización y la forma de comprensión del compromiso político debe entenderse de un modo dinámico y no restringido a una época específica: así, el sujeto hegemónico de un periodo histórico pervive en configuraciones posteriores con los nuevos sujetos -a los que incluso sirve como contrapunto identitario-, mientras que las organizaciones políticas van modificándose, intentando dar cabida a las subjetividades militantes emergentes más allá de su sentido operativo; por último, si bien la biografía heroica o edificante pierde vigencia a través del tiempo por su fuerte sesgo acrítico, aún es practicada bajo el formato testimonial, con diversos grados de criticismo renovado, conviviendo en la actualidad con la multifacética producción científica ${ }^{6}$.

En la historia contemporánea de la izquierda argentina tendriamos una primera configuración militante de tipo clásico conformada por el sujeto obrero o militante proletarizado (1), organizado en sindicato o en partidos políticos como el Partido Comunista, Partido Socialista (2), y que ha dejado huella bajo la forma de biografía militante de perfil "heroico" (3) o de militante que escribe la historia "oficial" de su organización política (tipo de fuente) ${ }^{7}$. Este ejemplo podría ser válido, grosso modo, para el comunismo y el socialismo argentino desde la década de los treinta hasta mediados de los sesenta.

En el mismo sentido, el entramado sociopolítico argentino muestra desde mediados del siglo XX a una clase obrera relativamente consolidada en términos identitarios, organizada en sindicatos, con predisposición a la acción y con una cultura política que reenvía a la forma partido, tanto en lo que refiere a la experiencia con el peronismo como a las demás organizaciones desplegadas por la izquierda como las recientemente mencionadas (Doyon, 2006; James, 2013; Torre, 2012). Es una clase obrera con tradición de lucha, es decir, que ha construido un habitus militante que conoce de protestas, movilizaciones, entre otras prácticas. Esta situación cambia a mediados de los sesenta cuando los fenómenos de la resistencia peronista, el surgimiento de la guerrilla, los movimientos de liberación nacional, la irrupción de la denominada "nueva izquierda", o el impulso de fenómenos de movilización como el Cordobazo, la emergencia del sindicalismo clasista (Tortti, 1999; Gordillo, Malecki y Schmucler, 2009), entre otros, revelan que estamos frente a una segunda configuración de tipo revolucionaria/insurreccional sin que esto signifique la desaparición de la forma anterior. Nuevamente podemos plan- 
De Prácticas y discursos

Universidad Nacional del Nordeste

Centro de Estudios Sociales

Año 7, Número 9, 2018, Marzo

ISSN 2250-6942

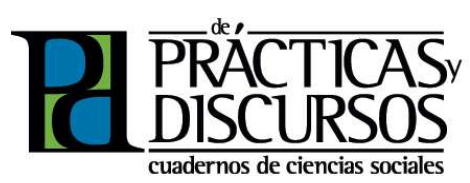

${ }^{8}$ Las críticas de época a este reforzamiento ciertamente acrítico del modelo de militante revolucionario son casi inexistentes, ver por ejemplo los escritos de Kaplan (1960) y Rozitchner (1966). tear el modo en que se configura este perfil militante epocal a través de las variables señaladas, contemplando los cambios en la estructura social y económica impactada por procesos de modernización capitalista aplicados bajo el "desarrollismo": 1) el sujeto militante se diversifica notablemente en términos de afirmación identitaria, aunque destaca su rasgo generacional y antisistémico (joven guerrillero, mujer comprometida, intelectual, sindicalista combativo, sacerdote tercermundista, etc.); 2) el tipo de organización también se amplía rebalsando a las existentes (partido, sindicato, ejército revolucionario, parroquia, barrio, movimiento campesino, revista cultural, universidad, etc.); 3) proliferan en consecuencia las producciones escritas de las propias organizaciones (periódicos, declaraciones, posicionamientos, revistas, libros, etc.) sobre la base de una necesidad de demarcarse políticamente al interior del campo militante (comunistas, maoistas, trotskistas, peronistas de izquierda, guevaristas, latinoamericanistas, etc.). El carácter "heroico" del militante no es puesto en cuestión como en el caso francés, al contrario, es reforzado en sus diversas manifestaciones bajo la impronta de la lucha revolucionaria y el horizonte de emancipación política como clima de época latinoamericano, claramente expuesto en la figura del Che Guevara y la experiencia revolucionaria cubana ${ }^{8}$. Una tercera configuración de tipo democratizante es posible plantear en el periodo denominado de transición democrática abierto en 1983, cuando parecen confrontar o superponerse viejos y nuevos modos de compromiso político que se debaten entre el fugaz reverdecer de la afiliación masiva a partidos políticos al calor del entusiasmo democrático (la "primavera alfonsinista") y, por otro lado, cierto desencanto o crisis respecto de la militancia clásica, visible en un lento abandono de la noción de revolución, muy afectada por la traumática experiencia dictatorial que media entre la segunda y tercera configuración militante (Ollier, 2009). En efecto, si la particularidad de las experiencias militantes latinoamericanas, y en particular la argentina, ha sido el atravesar durante los años sesenta-setenta un ciclo de ascenso de movilización/politización social seguido por otro de represión/desmovilización (1976-1983) signado por la experiencia inédita del terrorismo de Estado, podemos plantear la hipótesis que sostiene que las configuraciones militantes que emergen tras ese contexto cargan un "ethos democratizante" cuyo soporte es la renovada confianza en la democracia parlamentaria 
De Prácticas y discursos

Universidad Nacional del Nordeste

Centro de Estudios Sociales

Año 7, Número 9, 2018, Marzo

ISSN 2250-6942
Configuraciones militantes contemporáneas.

Una propuesta metodológica para pensar el compromiso político

Contemporary militant configurations.

A methodological proposal to think about political commitment

\begin{abstract}
${ }^{9} \mathrm{~A}$ lo que habría que agregar el impacto del eurocomunismo protagonizado por los principales PC de Europa.

${ }^{10}$ Un intelectual paradigmático que ilustra los debates teóricos de esta época en el ámbito europeo, y que recién será discutido décadas después en la Argentina, es Ernesto Laclau y su libro Hegemonía y estrategia socialista (1985).

11 Es interesante observar que para el caso de la revista Praxis, editada en la Argentina entre 1983-1986 (5 números en la calle), la mayor influencia teóricopolítica para desarrollar el debate sobre la "crisis de la militancia" proviene del campo intelectual francés, y en segundo término, del italiano.

${ }^{12}$ Como ejemplo del debilitamiento de la identidad clásica, tenemos al militante del modelo nacional-popular en crisis durante los años noventa, trabajado por Svampa y Martuccelli (1997). Una visión más polémica es la de Horowitz (2012) y su idea de "democracia de la derrota".
\end{abstract}

y sus instituciones combinado con un "desencanto" de la figura del militante clásico-heroico, asociado a la entrega de la vida por el objetivo revolucionario (Lesgart, 2002; Blanco et al., 2017)9. El militante pos dictadura es así un ciudadano de partido democrático, un sindicalista de frentes populares amplios, un intelectual comprometido con la vía democrática y la defensa de los DDHH y las instituciones republicanas ${ }^{10}$; en el mismo sentido, se restauran las organizaciones de izquierda clásicas (PC), otras se reconvierten (PST-MAS, PI) combinadas con cierta dinámica vecinalmovimientista (Jelin, 1987) que llevan adelante algunas nuevas expresiones militantes (organizaciones barriales, DDHH, etc.); al tiempo que comienzan a hacerse visibles lecturas críticas, si bien de circulación marginal, que problematizan el vínculo izquierda/ organización, democracia/socialismo y marcan la existencia de una crisis latente del modelo de militante revolucionario (Brocato, 1985; Tarcus y Rossi, 1985) que se acentuarán con el fracaso de los denominados socialismos reales ${ }^{11}$.

Por último, y sobre el trasfondo ahora renovado de otro desencanto respecto de las expectativas democráticas frustradas de cara a la experiencia de ajustes económicos en democracia, durante la década de los noventa y al calor de intensas protestas sociales contra la aplicación de políticas neoliberales se abre una cuarta configuración militante de tipo inestable, muy heterogénea, que presenta la crisis y persistencia de viejas configuraciones debilitadas ${ }^{12}$ con otras que denominariamos como configuraciones transicionales, esto es, formas de compromiso político sin pretensión hegemónica pero que ya nos muestran la senda de un posible análisis: los sujetos son múltiples, las organizaciones que los expresan presentan una gran diversidad (desde organizaciones de desocupados, trabajadores precarizados, vecinos, asambleistas, mujeres, pueblos originarios, partidos de izquierda clásicos, etc.), no pocas veces su existencia es fugaz - de alli su carácter inestable-, mientras que la novedad emerge también en los modos de estudio de las mismas: múltiples perspectivas de análisis se despliegan bajo etnografias, entrevistas orales, historias de vida, historias militantes y reconstrucciones históricas (Auyero, 2004). Desde mediados de los noventa comienzan a proliferar estudios producidos desde el ámbito académico sobre protestas y nuevos movimientos sociales influidos tanto por la escuela europea como por la corriente norteamericana (Giarraca, 2001; Schuster, Naishtat, Nardacchione, Pereyra, 2005; Schuster, 2006; Gordillo, 2010), o también se 
De Prácticas y discursos

Universidad Nacional del Nordeste

Centro de Estudios Sociales

Año 7, Número 9, 2018, Marzo

ISSN 2250-6942

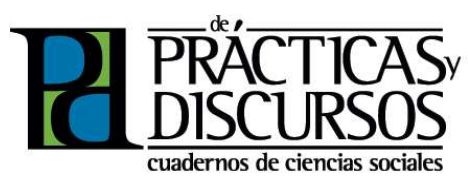

${ }^{13}$ Ver para el caso de la vertiente de centro izquierda peronista, o también identidad nacional popular, en Levistsky (2005), Svampa (2007) y AAVV (2009). muestran críticos hacia esas influencias (Gómez, 2014; Galafassi, 2006), manteniéndose esta tendencia hasta la actualidad, incluso generando las condiciones para un debate al interior del campo académico sobre el rol del intelectual ${ }^{13}$.

El escenario abierto donde encontramos esta cuarta configuración militante se extiende desde mediados de los años noventa (fenómenos de protesta social tales como las puebladas en Cutral Có y el posterior surgimiento de organizaciones piqueteras y del "sujeto" piquetero como novedad, p.e.), atraviesa la crisis sociopolítica de 2001, y cierra provisoriamente con la restauración del sistema político bajo el denominado kirchnerismo y su renovado llamado a la militancia juvenil desde el Estado (Natalucci y Pérez, 2013). Es decir, su soporte son las luchas sociales contra el neoliberalismo, luego la interpelación estatal; mientras, en el plano simbólico opera una profunda crisis de las izquierdas luego de la caída del Muro de Berlín y que se manifiesta como implosión de la forma-partido y explosión de organizaciones autónomas, descentralizadas, ancladas territorialmente y con una estrategia política difusa. Se comprende entonces el carácter en principio impreciso -insistimos: inestable- de esta configuración militante, agudizado por la fugacidad de muchas organizaciones nuevas y los reacomodamientos y tensiones que produjo la mencionada interpelación desde el Estado hacia los sujetos y organizaciones militantes.

\section{DEBATES ABIERTOS PARA UNA CONCLUSIÓN PROVISORIA}

Esta última etapa y su configuración militante ha convocado, dejándola en suspenso, la emergencia de un debate sobre qué es la militancia, cuál es su razón de ser, cuáles sus límites inmanentes, cómo se configuran los sujetos militantes, sus estrategias; empero, no se trata de una configuración en transición sin restricciones estructurales: precisamente, como hipótesis sostenemos que la condición de posibilidad de esta configuración militante transicional obedece a los efectos de una historia hecha cuerpo (Bourdieu, 2007) y que lleva sobre sus espaldas la dificultad en la construcción de proyectos políticos elaborados con vistas a alcanzar una sociedad alternativa. Del retorno a la democracia (1983) al último gran ciclo de protestas a fines del siglo XX, la Argentina acumula periodos de profundas crisis económico-sociales, crisis de los movimientos de resistencia y tensiones irresueltas en el campo intelectual. Se abre lugar así 
De Prácticas y discursos

Universidad Nacional del Nordeste

Centro de Estudios Sociales

Año 7, Número 9, 2018, Marzo

ISSN 2250-6942
Configuraciones militantes contemporáneas.

Una propuesta metodológica para pensar el compromiso político

Contemporary militant configurations. A methodological proposal to think about political commitment

\footnotetext{
14 "Carta de Oscar Del Barco" (2004), revista La Intemperie $\mathrm{N}^{\circ} 17$, Córdoba, publicada más tarde como compilación en No Matarás (2010).
}

para la construcción de configuraciones tan transitorias como de difícil encuadre empírico.

Ahora bien, si este planteo es acertado, ¿cuál sería el síntoma de época que ilustraría esta dificultad?, ¿dónde ubicar la bisagra que en la historia argentina -así como en la francesa es Mayo del 68- remite a un punto de inflexión respecto a pensar la condición militante?; al igual que el caso francés, una determinada coyuntura política generó en la Argentina la condición de posibilidad que abrió una hendija para el debate y la proliferación de escritos académicos y militantes: las protestas sociales de los noventa que culminaron en las míticas jornadas del 19 y 20 de diciembre de 2001, momento de cristalización de un sujeto beligerante diverso, joven, que lucha en la intemperie ideológica contra el deterioro de sus condiciones materiales de existencia pero que no es el militante clásico, ni el obrero sindicalizado, ni mucho menos el Partido.

Las postrimerias de ese 2001 generaron, a su tiempo, el clima donde ubicamos el conocido debate sobre la "responsabilidad" militante y que tomó forma de libro titulado No Matarás. Iniciado tras una carta que envía el reconocido intelectual cordobés Oscar Del Barco a la revista La Intemperie (fines de 2004) ${ }^{14}$ y que es en realidad una respuesta a otra entrevista a Héctor Jouvé sobre la violencia al interior de las organizaciones guerrilleras en los años sesenta en la Argentina, esa carta jugó como disparador de una serie de intervenciones más allá del caso en cuestión y provocó como nunca antes la reflexión crítica sobre el tópico de la militancia en sentido amplio. En efecto, en esas páginas podemos ubicar las coordenadas contemporáneas desde las cuales se ha releido el debate sobre la violencia revolucionaria en los sesenta-setenta desde el presente y en el cual han intervenido viejos y nuevos actores, militantes, académicos con o sin actividad política, protagonistas históricos e intérpretes actuales. Si bien la temática emerge sesgada por la pregunta filosófica sobre la práctica y la justificación de la violencia revolucionaria en las organizaciones políticas de izquierda, en especial en las guerrillas (la responsabilidad de la vida frente a un semejante y que además es un "compañero" de militancia, víctima de un fusilamiento a mano de sus pares), las intervenciones alli vertidas expresarian en sus derivas ciertas reiteraciones o incomodidades que exceden ese locus al pensar el problema de la acción condicionado ya por el contexto histórico, ya por su rechazo en clave 
De Prácticas y discursos

Universidad Nacional del Nordeste

Centro de Estudios Sociales

Año 7, Número 9, 2018, Marzo

ISSN 2250-6942

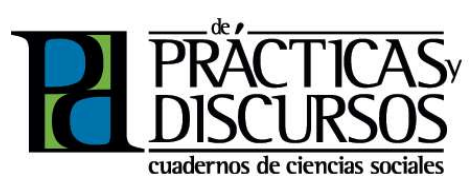

15 Svampa (2007) ha sido quien más ha desarrollado esta cuestión planteando la figura del "intelectual anfibio", es decir, aquel que interviene críticamente -y se compromete- en y a favor de los movimientos sociales, pero sin que ello implique descuidar la especificidad de su trabajo en el campo académico. hermenéutica (y acudiendo a la ética, explicitada en el título de la compilación), ya por la lógica organizacional y la rigidez del modelo militante; aún más, ese condicionante de origen respecto del debate, si bien puede leerse como parte de las reglas de juego del mismo (un saldar cuentas con el pasado militante del propio Oscar del Barco), imposibilita el desplazamiento desde la justificación de la acción hacia una región quizás más comprensiva: el por qué existe, y fundamentalmente se practica la militancia en la forma en la que se observa en la historia.

Desde el punto de vista de las configuraciones militantes no resulta casual ni quien comienza el debate (un intelectual, filósofo, exiliado, ex militante del PC durante los sesenta-setenta), el lugar en que se despliega inicialmente (una revista intelectual de Córdoba), ni el momento histórico en que comienza a publicarse lo que decantará en dos extensos volúmenes: estamos hablando de los años inmediatos posteriores a las movilizaciones del vertiginoso año 2001, señalado como el punto de inflexión de nuevas y viejas formas de hacer política, pero también marcado por cierto desencanto en el terreno de las izquierdas frente a la deriva inmediata del "que se vayan todos", esto es, la consigna que homogeneizó las luchas en torno a las protestas de 2001, y que fue presentado por algunos autores también como una crisis de mayor alcance en la identidad de la vieja izquierda (Adamovsky, 2007), o en una dimensión de largo plazo, como un periodo marcado por la derrota del movimiento obrero pos dictadura (Ghigliani, 2008).

Resumiendo, en las últimas dos décadas presenciamos un escenario histórico y político donde se superponen dos debates que reenvían a la cuestión del militante y el compromiso político: el de la violencia revolucionaria en la militancia de los sesentasetenta, y otro que cruza la discusión sobre viejas y nuevas formas de militancia de cara al nuevo siglo y que reincorpora, como ya se dijo, el lugar del intelectual en la política ${ }^{15}$. Este último aspecto se explica en parte por la abundancia de libros, artículos, revistas científicas y políticas, tesis, centros de investigación y de documentación de las izquierdas, que emergen atravesados por la renovada discusión sobre los setenta de la que participó también el propio Estado practicando a partir de 2003 un relato reivindicativo de esa militancia acompañado de la construcción de centros memoriales y estatizando efemérides (tales como el 24 de marzo) que legitiman y resignifican la lucha por los DDHH. De alli que la inestabilidad o perfil transitorio de esta configura- 
De Prácticas y discursos

Universidad Nacional del Nordeste

Centro de Estudios Sociales

Año 7, Número 9, 2018, Marzo

ISSN 2250-6942
Configuraciones militantes contemporáneas.

Una propuesta metodológica para pensar el compromiso político

Contemporary militant configurations. A methodological proposal to think about political commitment

\footnotetext{
${ }^{16}$ Sin olvidar el propio debate interno que mantiene la obra de Bourdieu con las posiciones políticas y filosóficas de Sartre respecto de la voluntad y la acción. Ver Razones prácticas. Sobre la teoría de la acción (1991) y El sentido práctico (2007).
}

ción militante se comprenda mejor en esta encrucijada histórica. Con todo, el particular modo que adquirió la politización de este debate, la más de las veces materializado en publicaciones testimoniales -y encerrado entre el callejón ético o el mandato histórico- o en descripciones de prácticas militantes en el caso del campo académico, deja entrever una ausencia: la pregunta por la condición militante y la razón práctica de su intervención: ¿qué es un militante en la época contemporánea?, ¿cómo abordar su lógica de acción?, ¿en qué horizonte de sentido ubicar las trasformaciones en los modos de compromiso político?, ¿qué nos dicen las prácticas sobre cómo es concebida la actividad política? Atravesado por dimensiones culturales, políticas y económicas, el militante es un sujeto colectivo, generalmente organizado, referenciado por diversos tipos de afinidades ideológicas, y cuyo imaginario reenvía a ese esfuerzo del sujeto moderno por generar, incentivar o dinamizar la acción hacia un determinado fin en las más diversas formas. Su existencia, su pervivencia, refleja la actualidad y complejidad del problema de la acción y del compromiso político que no puede reducirse ni a describir una práctica ni a trazar un decurso biográfico: detrás de ella (o adelante) habrá que dar cuenta de la construcción de una disposición y de la lógica de una práctica, que se debate entre la reflexividad actual y el inescindible forzamiento voluntarista tal como lo describe Badiou. Nuestra propuesta de pensar en configuraciones militantes ancla sobre esa encrucijada, es decir, la acción militante y a los militantes contemporáneos desde una perspectiva histórica, pero que también piense en una razón práctica en el sentido que le otorga Bourdieu a las prácticas sociales ${ }^{16}$, especificando aqui que nos referimos a un tipo particular de acción: la que llevan adelante los militantes de izquierda.

Finalmente, en esta encrucijada encontramos la cuestión del compromiso político, fundamental para evitar reducir al militante a una mera función operativa referida a la movilización: la realización del compromiso en el sujeto constituye su relación con lo real y con la verdad en el sentido de un valor moral que compromete, a través del tiempo, bajo la forma de trayectoria, y que excede lo individual al ser objeto de aprendizajes, saberes y competencias en el seno de organizaciones. El compromiso es una puesta en relación con otros mediante actos; pero su comprensión debe inscribirse en el momento previo donde nace o es decidido el compromiso, también entendido como responsabili- 
De Prácticas y discursos

Universidad Nacional del Nordeste

Centro de Estudios Sociales

Año 7, Número 9, 2018, Marzo

ISSN 2250-6942

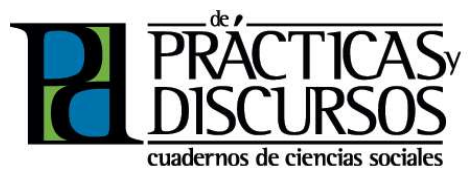

dad. Ese antes suele ser un acontecimiento, algo que en su contingencia adviene frente al sujeto y se transforma en operador de compromiso, o en otras palabras, en factor de elección, de toma de decisión (Giraud, 2013). El compromiso tiene además la particularidad de ocurrir oscilando entre situaciones de hecho que comprometen per se (una convicción razonada) y un endoso o carga adquirido tras la ponderación de una contingencia cualquiera que afecta al sujeto y lo decide a comprometerse (una muerte, un acontecimiento desestabilizador, etc.). Al respecto, Giraud destaca que el compromiso se ejerce como una puesta en escena, despliega una lógica de acción, pues es algo que se muestra o pone en evidencia ante otros: una protesta social, un mitin, un debate, incluso un testimonio; ese juego ante otros constituye un lazo social que suele revalidarse en la práctica cotidiana, pero como todo lazo no es de ningún modo definitivo, es decir, puede debilitarse o romperse por ese mismo ejercicio militante cuando este se percibe rutinario, dando lugar a un movimiento de cuestionamiento respecto del modo dominante del ser militante, de la práctica como "objeto-soporte" del compromiso (Giraud, 2013:59), sin que ello implique renunciar al credo de compromiso. Esta aparente renuncia es lo que se conoce en la jerga militante como traición. Sin embargo, y a pesar de denotar un descompromiso, es la traición la que permite comprenderlo cabalmente, ya que el contenido de la acusación pone en evidencia el canon dominante, el "código ético" (Longoni, 2007) que rige las organizaciones militantes, tal como el debate sobre el No Matarás lo demuestra. En otras palabras, para traicionar hay que haber estado previamente comprometido, haber sido leal, conocer las reglas, los símbolos, la doctrina, la interpretación de los libros. Más aún, si la creencia no ha sido abandonada, sino más bien rectificada, tal el caso de los que se apartan y fundan nuevas organizaciones reorientando un compromiso, entonces tenemos, vía traición, una radicalización del compromiso, lo que convierte a la traición en un momento crucial del compromiso. Frente a este escenario, y a esta época ciertamente desencantada con el clásico mandato del militante heroico tal como lo señala la cita inicial de Badiou, e indicada por Giraud como de superposición o desplazamiento del objeto de compromiso hacia formas de "realización de sí mismo", queda una propuesta de pensar a través de la descripción del despliegue militante en redes, trayectorias, conexiones y del flujo de las acciones; un despliegue

| PAGINA 154| DOSSIER | 
que evidencie cómo unos hacen mover a otros pero suspendiendo, como sugiere De Beauvoir, aquel mandato causal de encontrar quien comenzó el movimiento, qué fuerza está "detrás" de la acción o cuál ética de la voluntad la sostiene; sin dudas, estos elementos son determinantes para comprender cómo se configura un militante de época, aunque no al precio de condicionar la explicación forzando una coherencia entre discurso y práctica. Se trata de asir una concatenación de eventos para seguir algún guion que de ningún modo está predefinido. Una explicación es una descripción en donde más que buscar causas se deben dar cuenta de las transformaciones que producen el movimiento (la acción) de los sujetos (militantes) en un determinado tiempo histórico, ayudando a reflexionar sobre los diversos modos en que se configuran subjetividades militantes vinculadas al compromiso político en la época contemporánea.

BIBLIOGRAFÍA

ADAMOVSKY, E. (2007). Más allá de la vieja izquierda. Buenos Aires: Prometeo.

AAW (2009). De minifaldas, militancias y revoluciones. Buenos Aires: Ediciones Luxemburg.

AAW. (2009). Dossier: Pensar la relación entre intelectuales e izquierda en América Latina hoy. Revista Nuevo Topo, Buenos Aires.

AAW. (2010). No Matarás. Sobre la responsabilidad (Vol. I y II). Córdoba: Universidad Nacional de Córdoba.

ALMEYRA, G. (2013). Militante crítico. Buenos Aires: Continente.

ARICÓ, J. (1999). Entrevistas, 1974-1991. Córdoba: Universidad Nacional de Córdoba.

AUYERO, J. (2004). Vidas beligerantes. Buenos Aires: Universidad Nacional de Quilmes.

BADIOU, A. (2005). El siglo. Buenos Aires: Manantial.

BLANCO, R.; NÚÑEZ, P.; VÁZOUEZ, M. Y VOMMARO, P. 
(2017). Militancias juveniles en la Argentina democrática. Trayectorias, espacios y figuras del activismo. Buenos Aires: Imago Mundi.

BROCATO, C. (1985). La Argentina que quisieron. Buenos Aires: Planeta.

BOURDIEU, P. (1996). Cosas dichas. Barcelona: Gedisa.

(2001). El campo político. Bolivia: Plural.

(2007). El sentido práctico. Buenos Aires: Siglo XXI.

DE BEAUVOIR, S. (1972) ¿Para qué la acción? Buenos Aires: La Pléyade.

DOYON, L. (2006). Perón y los trabajadores. Los orígenes del sindicalismo peronista, 1943-1955. Buenos Aires: Siglo XX.

FILLIEULE, O. Y TARTAKOWSKY, D. (2015). La manifestación. Buenos Aires: Siglo XXI.

GALAFASSI, G. (2006). Cuando el árbol no deja ver el bosque. Neofuncionalismo y posmodernidad en los estudios sobre movimientos sociales. Revista Theomai, 14. Disponible on line: http:// revista-theomai.unq.edu.ar/numero14/ArtGalafassi.pdf

GHIGLIANI, P. (2008). Los usos de la noción de derrota en la historia reciente del movimiento obrero. En $\mathrm{V}$ Jornadas de Sociología de la Universidad Nacional de La Plata.

GIARRACCA, N. (2001) (COMP.) La protesta social en Argentina. Transformaciones económicas y crisis social en el interior del pais. Buenos Aires: Alianza.

GILBERT, I. (2009). La Fede. Alistándose para la revolución. Buenos Aires: Sudamericana.

GIRAUD, P. (2013) ¿Qué es el compromiso? Buenos Aires: Unsam.

GOFFMAN, E. (2006). Frame Analysis. Los marcos de la experiencia. España: Centro de Investigaciones Sociológicas, Siglo XXI. 
GÓMEZ, M. (2014). El regreso de las clases. Clases, acción colectiva y movimientos sociales. Buenos Aires: Biblos.

GORDILLO, M. (2010). Piquetes y cacerolas... El "Argentinazo" del 2001. Buenos Aires: Sudamericana.

GORDILLO, M.; MALECKI, S. Y SCHMUCLER, H. (2009). Obrerismo de pasado y presente para un dossier sobre SITRAC SITRAM. Buenos Aires: Ediciones Al margen.

GRAMSCI, A. (2011). Odio a los indiferentes. Barcelona: Ariel. Hobsbawm, E. (1978). Revolucionarios. Ensayos contemporáneos. Buenos Aires: Ariel.

HOROWITZ, A. (2012). Las dictaduras argentinas. Historia de una frustración nacional. Buenos Aires: Edhasa.

JAMES, D. (2013). Resistencia e integración. El peronismo y la clase trabajadora argentina. Buenos Aires: Sudamericana.

JELIN, E. (1987). Movimientos sociales y democracia emergente (Vol. 2). Buenos Aires: Ceal.

KAPLAN, M. (1960). Política y vida cotidiana. Buenos Aires: Praxis.

LACLAU, E. (1985). Hegemonía y estrategia socialista. Buenos Aires: Siglo XXI.

LESGART, S. (2002). Usos de la Transición a la Democracia. Ensayo, Ciencia y Política en la Década del Ochenta. Revista Estudios Sociales, 1(22), 163-185.

LEVITSKY, S. (2005). La transformación del justicialismo. Del partido sindical al partido clientelista, 1983-1999. Buenos Aires: Siglo XXI.

LONGONI, A. (2007). Traiciones. Buenos Aires: Norma.

MCADAM, D.; MCCARTHY, J.D. Y ZALD, M.N. (1996). Comparative Perspectives on Social Movements. Cambridge: University Press.

MC ADAM, D. (1999). The biographical impact of the activism. 
In Giugni, Mc Adam, Tilly (edit.) How social movements matter. EEUU: University of Minnesota Press.

MAGRI, L. (2011). El sastre de Ulm. El comunismo en el siglo XX. Buenos Aires: Clacso.

NADRA, A. (2013). Secretos en rojo. Un militante entre dos siglos. Buenos Aires: Corregidor.

NATALUCCI, A. Y PÉREZ, G. (2013). Vamos las bandas. Organizaciones y militancia kirchnerista. Buenos Aires: Nueva Trilce.

OLLIER, M. (2009). De La revolución a la democracia. Cambios privados, públicos y políticos de la izquierda argentina. Buenos Aires: Siglo XXI.

OLSON, M. (1966). The logic of collective action. EEUU: Harvard University Press.

OVED, I. (1978). El anarquismo y el movimiento obrero en $\mathrm{Ar}$ gentina. México: Siglo XXI.

PEIRANO, M. (1995). A favor de la etnografía. Río de Janeiro: Relume Dumará.

PEREYRA, D. (2014). Memorias de un militante internacionalista. Buenos Aires: Ediciones RyR.

POZZI, P. (2013). Sobre entrevistas activistas y militante. En Pensado, P. (coord.) Experimentar la izquierda. Historias de militancia en américa latina, 1950-1990. Buenos Aires: Clacso.

PUDAL, B. (2011). Enfoques teóricos y metodológicos de la militancia. Revista de Sociología, 25, 17-35, Chile.

ROSSANDA, R. (2008). La muchacha del siglo pasado. S/s: Ediciones Foca.

ROZITCHNER, L. (1966). La izquierda sin sujeto. La Rosa blindada, 9, Buenos Aires.

SCHUSTER, F. (2006). Transformaciones de la protesta social en 
Argentina 1989-2003. Cuadernos de Trabajo, 48, IGG, Gepsac. Disponible on line: http://webiigg.sociales.uba.ar/Publicaciones/DT/dt48.pdf

SCHUSTER, F.; NAISHTAT, F.; NARDACCHIONE, G. Y PEREYRA, S. (2005). Tomar la palabra. Estudios sobre protesta social y acción colectiva en la argentina contemporánea. Buenos Aires: Prometeo.

SURIANO, J. (2002). Anarquistas. Cultura y política libertaria en Buenos Aires, 1890-1910. Buenos Aires: Manantial.

SVAMPA, M. Y MARTUCCELLI, D. (1997). La plaza vacía. Las transformaciones del peronismo. Buenos Aires: Losada.

SVAMPA, M. (2007) ¿Hacia un nuevo moldeo intelectual? Revista $\tilde{N}$, Diario Clarín, Buenos Aires.

TARCUS, H. Y ROSSI, L. (1985). Militancia y revolución (la crisis de un modelo). Revista Praxis, Año III, 5, 3-28.

TARROW, S. (1998). Power in Movement. Nueva York: Cambridge University Press.

TILLY, C. (2008). Contentious Performances. Cambridge: Cambridge University Press.

TORRE, J.C. (2012). Ensayos sobre movimiento obrero y peronismo. Buenos Aires: Siglo XXI.

TORTII, M.C. (1999). Protesta social y "nueva izquierda" en la Argentina del Gran Acuerdo Nacional. En Pucciarelli, A. (ed.) La primacía de la política. Lanusse, Perón y la Nueva Izquierda en tiempos del GAN (pp. 205-230). Buenos Aires: Eudeba.

TRAVERSO, E. (2017). Left-Wing Melancholia. Marxism, History, and Memory. EEUU: Columbia University Press.

WEIL, S. (2010). La condición obrera. Buenos Aires: Cuenco de Plata.

WILLIAMS, R. (1980). Marxismo y literatura. Barcelona: Península. 